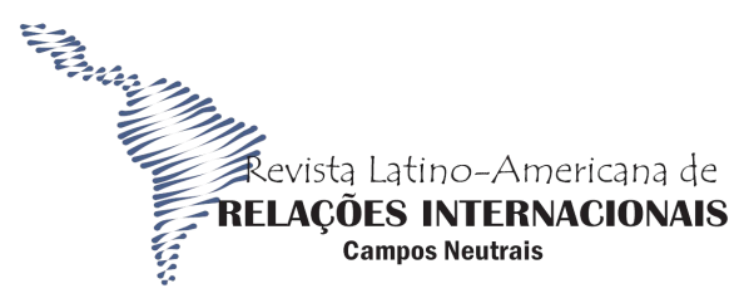

\title{
Delação premiada e a Operação Lava-Jato
}

\author{
Marcia Leite Borges \\ Luciano Duarte da Silva
}

\begin{abstract}
Resumo: O presente trabalho trata da utilização do instituto da delação premiada nas investigações do esquema de corrupção e lavagem de dinheiro envolvendo os dirigentes da Petrobras, agentes políticos e grandes empreiteiras do país. Esta Operação fico conhecida como Lava Jato e teve sua fase ostensiva iniciada em 2014, quando a partir de monitoramento telefônico das conversas do doleiro Carlos Habib Chater, foi possível identificar diversas organizações criminosas comandadas por doleiros e relacionadas entre si. Neste sentido, a investigação procurou analisar os impactos e a forma procedimental da delação premiada nos processos instaurados a partir das investigações realizadas pela Lava Jato, compreendendo as minúcias em relação à delação premiada nas investigações sobre corrupção no Brasil. A problemática gira em torno da seguinte questão: De que maneira o instituto da delação premiada tem contribuído no processo investigativo dos crimes de corrupção e lavagem de dinheiro, no âmbito da Operação Lava Jato? A metodologia utilizada no presenta trabalho é a pesquisa bibliográfica. É possível perceber, que mesmo diante das críticas, a favor ou contra, à utilização dos acordos de delação premiada, quando analisados os resultados obtidos, até o momento, se observa que esse instituto tem sido de grande valia ao desmantelamento das organizações criminosas envolvidas, à recuperação do ativo financeiro aos cofres públicos brasileiro e à continuidade do processo investigativo da Operação Lava Jato.
\end{abstract}

Palavras-chave: Delação Premiada; Corrupção; Lavagem de Dinheiro

\section{Awarded plea bargain and WashLava-Jato Operation}

\begin{abstract}
The present work deals with the use of the institute of the awarded plea bargain in the investigations of the corruption and money laundering scheme involving the leaders of Petrobras, political agents and major contractors in the country. This Operation is known as Lava Jato and had its ostensive phase started in 2014, when, through telephone monitoring of the conversations of the money changer Carlos Habib Chater, it was possible to identify several criminal organizations led by money changers and related to each other. In this sense, the investigation sought to analyze the impacts and the procedural form of the plea bargain in the proceedings initiated from the investigations carried out by Lava Jato, understanding the minutiae in relation to the plea bargain in the investigations on corruption in Brazil. The problem revolves around the following question: In what way has the institute of the prizewinning complaint contributed to the investigative process of crimes of corruption and money laundering, within the scope of Operation Lava Jato? The methodology used in this work is bibliographic research. It is possible to perceive that even in the face of criticism, for or against, the use of award-winning agreements, when analyzing the results obtained,
\end{abstract}

\begin{tabular}{|c|c|c|c|c|}
\hline $\begin{array}{c}\text { CAMPOS NEUTRAIS } \\
\text { REVISTA LATINO-AMERICANA DE RELAÇÕES INTERNACIONAIS }\end{array}$ & Rio Grande & v. 3 , n. 2 & p. $127-142$ & Maio-Ago 2021 \\
\hline
\end{tabular}


until now, it is observed that this institute has been of great value in the dismantling of the criminal organizations involved, the recovery of the financial asset to the Brazilian public coffers and the continuity of the investigative process of Operation Lava Jato.

Keywords: Awarded Delation; Corruption; Money laundry

\section{Introdução}

Nos últimos anos, através dos mais diversos meios de comunicação, falou-se muito sobre "delação premiada", principalmente, no que tange as investigações de corrupção e de lavagem de dinheiro relacionadas à Operação Lava Jato. No ordenamento jurídico, a conhecida "delação premiada" está presente em inúmeras legislações, tais como a Lei no 9.034/85 - Lei Contra o Crime Organizado; a Lei n ${ }^{\circ}$ 7.492/86 - Lei dos Crimes Contra o Sistema Financeiro; a Lei $n^{\circ}$ 9.613/98 - Lavagem de Capitais; e em especial a Lei $n^{\circ}$ 12.850/2013 - Organização Criminosa.

O tema é tratado em diversas convenções internacionais, cujo Brasil é signatário. No período Pós-Operação Lava Jato, a realização de acordos de colaboração, em especial, as delações premiadas se tornaram artifícios habituais para a obtenção de provas. Contudo, pouco se comenta sobre as suas características legais e as suas implicações nos processos de investigação. Por esta razão, faz-se de extrema importância o debate sobre a "delação premiada", tendo em vista, a utilização desse instituto gerar acirrados debates com opiniões divergentes.

Neste contexto, surgem diversos questionamentos a respeito da delação premiada e suas consequências no andamento das investigações. Porém, com o intuito de delimitar a temática, as seguintes questões nortearão o trabalho: De que maneira o instituto da delação premiada tem contribuído no processo investigativo dos crimes de corrupção e lavagem de dinheiro, no âmbito da Operação Lava Jato?

Para tanto, utilizar-se-á o método dedutivo, ou seja, partindo do geral para o particular, buscando analisar os impactos e a forma procedimental da delação premiada nos processos instaurados a partir das investigações realizadas pela Operação Lava Jato, compreendendo as minúcias em relação a este instituto nas investigações sobre corrupção no Brasil.

Para tanto, realizou-se uma revisão bibliográfica dos principais juristas e autores que tratam sobre a delação premiada, corrupção e lavagem de dinheiro. Além disso, o entendimento do arcabouço jurídico que trata dessas questões é extremamente relevante na 


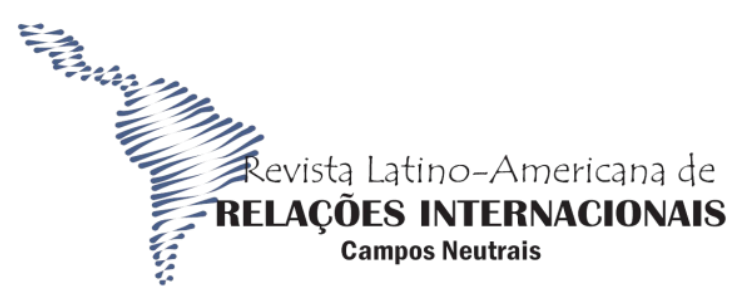

FURG

análise das implicações da utilização do instituto da delação premiada, em especial na Operação Lava Jato.

Inicialmente, serão trabalhos os conceitos de corrupção, lavagem de dinheiro e seu tratamento no ordenamento jurídico brasileiro. Na sequência, será desenvolvido um tópico específico a respeito da delação premiada contendo suas principais características. $\mathrm{O}$ terceiro tópico trata especificamente sobre a Operação Lava-Jato, realizando um apanhado geral dos principais eventos ao longo da investigação. O último tópico do desenvolvimento relacionará os resultados da delação premiada, na Operação Lava Jato, com as principais críticas a utilização deste instituto nas investigações sobre lavagem de dinheiro e corrupção no país. A sequência da investigação possibilitará a reflexão, nas considerações finais, do impacto da delação premiada como instrumento de obtenção de provas e de colaboração na Lava Jato.

\section{Fundamentação Conceitual: corrupção e lavagem de dinheiro}

A delação premiada tem sido um tema recorrente nos debates jurídicos e nas conversas informais da sociedade em geral, desde o início das investigações de corrupção e lavagem de dinheiro realizadas pela Operação Lava Jato. Contudo, antes de iniciar o debate diretamente sobre as implicações das delações premiadas no processo investigativo em questão, se faz necessária a identificação de alguns conceitos-chaves deste trabalho, tais como corrupção, lavagem de dinheiro e o próprio conceito de delação premiada.

A corrupção não é uma prática recente, ela tem habitado nas sociedades ao longo dos tempos. No Brasil, as posturas corruptas não emergiram especificamente nas últimas décadas, elas têm sido presenças constantes desde as bases da colonização do país e continuam presentes. Uma das explicações para a manutenção da corrupção é a relação "doente" entre o Estado e a sociedade, onde se confunde entre o que é público e o que é privado.

O termo "corrupção" não apresenta um conceito uno ou consensual, sendo de difícil delimitação. De acordo com Miranda (2018, p. 238), "esta dificuldade vem da aparência de

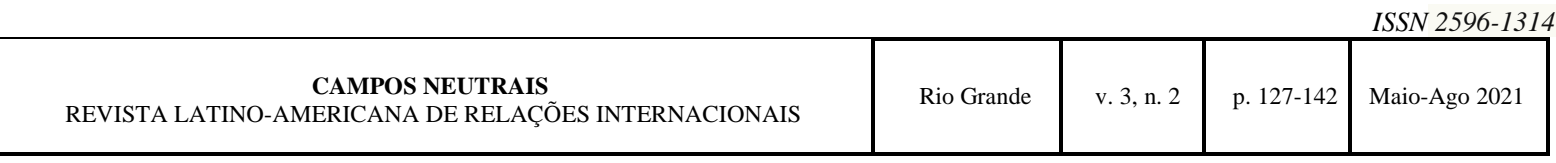


que se trata de uma simples questão semântica, em que, na verdade, a maneira com que se define corrupção também determina o que irá ser modelado e medido".

Dentre os diversos autores que tratam desta conceituação pode-se destacar aquela elaborada por Hodess (2004), que é utilizada pela Transparência Internacional ${ }^{1}$ (TI). Nesta definição, a corrupção é vista como "o abuso de um poder incumbido a líderes políticos para ganhos privados, com o objetivo de se aumentar o poder ou a riqueza" (2004, p. 11). Neste mesmo sentido, os autores Araújo e Sanchez (2005, p. 140), conceituam a corrupção como “o uso do poder de um cargo público, à margem da lei, para obtenção de ganhos privados".

Ambos os conceitos demonstram que a postura corrupta tem uma ligação direta com ganhos privados, ligados estreitamente ao setor público. Tal abordagem contempla posturas corruptas, porém, se torna limitada em sua abrangência.

Por esta razão, o presente trabalho se utilizará do conceito apresentado por Miranda (2018, p. 265) que denomina a corrupção como “o pagamento (financeiro ou não) para a obtenção, aceleração ou para que haja ausência de um serviço feito por um funcionário público ou privado. A motivação da corrupção pode ser pessoal ou política tanto para quem corrompe quanto para quem é corrompido”. Esta visão está descrita na figura 1.

Figura 1

Descrição do Conceito de Corrupção Formulado por Miranda - 2018

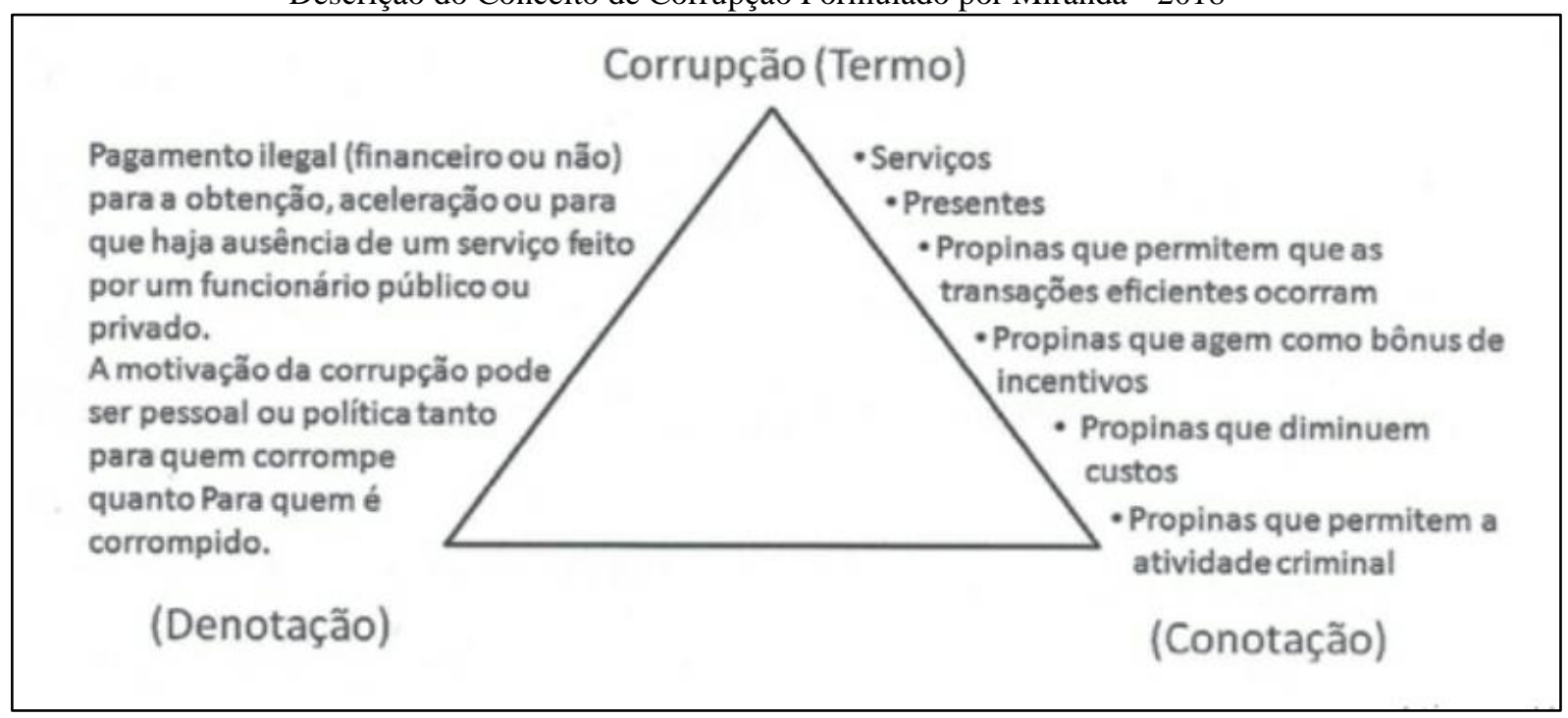

Fonte: Miranda, 2018, p. 261.

\footnotetext{
1 "um movimento global com uma mesma visão: um mundo em que governos, empresas e o cotidiano das pessoas estejam livres da corrupção" (TI, 2019).
} 


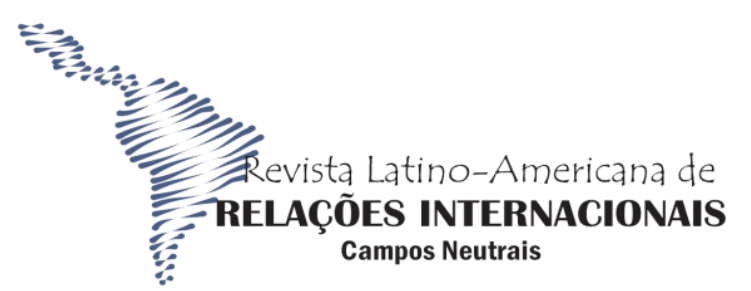

FURG

Conforme pode ser observado na figura acima, este último conceito amplia a percepção da corrupção, de uma esfera unicamente pública para, também, uma esfera privada.

Com relação à "lavagem de dinheiro", embora o Brasil tenha se comprometido internacionalmente em reprimi-la, quando assinou a Convenção das Nações Unidas contra o Tráfico Ilícito de Entorpecentes e Substâncias Psicotrópicas, ocorrida em 1988, em Viena, e que foi ratificada em 1991, pelo Decreto $\mathrm{n}^{\circ}$ 154/91, apenas uma década após a referida Convenção, foi aprovada a Lei no 9.613/98 tipificando o crime de "lavagem" ou ocultação de bens, direitos e valores.

Grosso modo, pode-se dizer que a "lavagem" de dinheiro é a atividade que realiza a transformação dos lucros provenientes de ações ilegais em ganhos aparentemente legais. Segundo a Lei 9.613/98, lavagem de dinheiro é definida como "ocultar ou dissimular a natureza, origem, localização, disposição, movimentação ou propriedade de bens, direitos ou valores provenientes, direta ou indiretamente, de infração penal" (BRASIL, 1998, Art. $\left.1^{\circ}\right)$.

A legislação em questão, especificava os crimes que se enquadrariam como lavagem de dinheiro:

\footnotetext{
I - de tráfico ilícito de substâncias entorpecentes ou drogas afins;

II - de terrorismo;

III - de contrabando ou tráfico de armas, munições ou material destinado à sua produção;

IV - de extorsão mediante sequestro

V - contra a Administração Pública, inclusive a exigência, para si ou para outrem, direta ou indiretamente, de qualquer vantagem, como condição ou preço para a prática ou omissão de atos administrativos;

VI - contra o sistema financeiro nacional;

VII - praticado por organização criminosa (BRASIL, 1998, Art. 1).
}

Com a alteração da Lei 9.613/98, através da Lei n 12.683/12, ocorreu a ampliação da abrangência da legislação penal, não estando mais vinculada apenas as infrações penais taxativas e estanques, como especificado, anteriormente.

Neste sentido, é possível identificar a lavagem de dinheiro como um crime acessório, utilizado para legalizar os bens provenientes, não só de crimes referentes ao tráfico de

\begin{tabular}{|c|c|c|c|c|}
\multicolumn{1}{|c|}{ ISSN 2596-1314 } \\
\begin{tabular}{|l|l|l} 
CAMPOS NEUTRAIS \\
REVISTA LATINO-AMERICANA DE RELAÇÕES INTERNACIONAIS
\end{tabular} & Rio Grande & v. 3, n. 2 & p. 127-142 & Maio-Ago 2021 \\
\hline
\end{tabular}


entorpecentes, mas de outros crimes, entre eles os relacionados à corrupção (MINISTÉRIO DA ECONOMIA, 2015).

A pena estipulada para este tipo de infração varia de três a dez anos de reclusão, mais multa. Todavia, a pena "será aumentada de um a dois terços, se os crimes definidos nesta Lei forem cometidos de forma reiterada ou por intermédio de organização criminosa" (BRASIL, 2012, Art. $1^{\circ}, \S 4^{\circ}$ ). A referida lei também estipula a possibilidade (facultada ao juiz, o aceite ou a substituição, a qualquer tempo) de redução de pena e a possibilidade de cumpri-la em regime aberto ou semiaberto, caso o infrator colabore de forma espontânea e essa colaboração acarrete a "apuração das infrações penais, à identificação dos autores, coautores e partícipes, ou à localização dos bens, direitos ou valores objeto do crime" (BRASIL, 2012, Art. 1, § 5º.

A possibilidade de redução de pena pela colaboração, dita aqui como delação premiada (que será explicada a seguir), tem sido um tema recorrente, isso porque tem gerado opiniões contrárias em relação a suas contribuições e implicações nas investigações ligadas à corrupção e à lavagem de dinheiro no país.

\section{Delação Premiada: conceito, legislação e características}

$\mathrm{O}$ ato de delatar significa:

[...] acusar, denunciar, revelar. Processualmente, somente tem sentido falarmos em delação, quando alguém, admitindo a prática criminosa, revela que outra pessoa também ajudou de qualquer forma. Esse é um testemunho qualificado, feito pelo indiciado ou acusado. Naturalmente, tem valor probatório, especialmente porque houve admissão de culpa pelo delator (NUCCI, 2008a, p. 432).

O instituto da delação pode ser concedido com ou sem vantagens ao delator. Quando ele ocorre com benefícios, é convencionalmente denominado delação premiada, ou seja:

[...] um instrumento jurídico-penal de investigação criminal para a obtenção de provas, em que o delator e/ou colaborador fornece as informações exigidas por lei, obtendo do Estado um incentivo, ou seja, um benefício, ante a opção tomada voluntariamente - em contribuir com o sucesso da persecução criminal (BORGES, 2016).

Para Aras (2015), a delação premiada é apenas uma das quatro subespécies da colaboração premiada: "delação premiada"; "colaboração para libertação"; "colaboração para localização e recuperação de ativos"; "colaboração preventiva":

[...] "delação premiada”, o colaborador expõe as outras pessoas implicadas no crime e seu papel no contexto delituoso, razão pela qual o denominamos de agente revelador. Na hipótese de "colaboração para libertação”, o agente indica o lugar onde está a pessoa sequestrada ou o refém. Já na "colaboração para localização e recuperação de ativos", o autor fornece dados para a localização do produto ou 


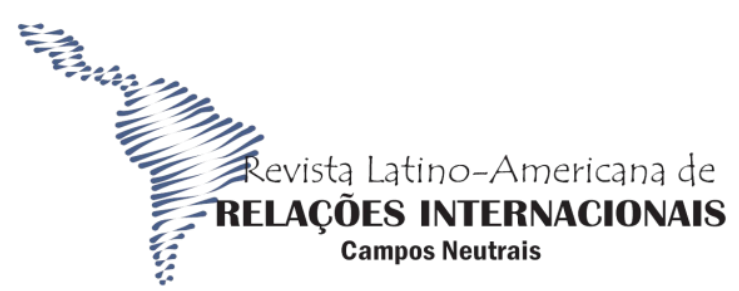

FURG

proveito do delito e de bens eventualmente submetidos à lavagem. Por fim, há a "colaboração preventiva", na qual o agente presta informações relevantes aos órgãos de persecução para evitar um crime, ou impedir a continuidade ou permanência de uma conduta ilícita (ARAS, 2015).

Contudo, para Gilson Dipp (2015, p. 9) o instituto da delação premiada é a “denominação popular da chamada colaboração premiada instituída pela Lei n ${ }^{\circ} 12.850$, de 2 de agosto de 2013". Isso, porque, segundo Levorin (2018), a referida Lei convencionou chamá-la de colaboração premiada, "em razão do significativo questionamento ético que pesa sobre a conduta de delatar, a traição como forma de obtenção de vantagem e o estigma de dedo-duro" (2018, p. 122).

Para fins deste trabalho, será utilizado o termo "delação premiada" como sinônimo de "colaboração premiada", tal qual, a utilização realizada por Dipp (2015).

Para que possa ser utilizado o instituto da delação premiada, e para que o acordo seja firmado entre o colaborador e o Ministério Público, "não basta a simples confissão ou incriminação de terceiros. Para que o colaborador se beneficie, deve-se afastar das práticas delitivas e contribuir de maneira efetiva para a coleta de provas importantes tendentes a confirmar as revelações" (ENCCLA, 2014, p. 02).

As informações prestadas devem possibilitar a determinação os fatos e acontecimentos auxiliando no desmantelamento de organização criminosa e na recuperação do produto do crime (ENCCLA, 2014). Sendo assim, é possível que o juiz não homologue o acordo de delação se os requisitos legais não forem atendidos ou sua contribuição não seja adequada ao caso concreto (BRASIL, 2013).

É importante frisar que, com o instituto da delação premiada "o juiz poderá, a requerimento das partes, conceder o perdão judicial, reduzir em até 2/3 (dois terços) a pena privativa de liberdade ou substituí-la por restritiva de direitos daquele que tenha colaborado efetiva e voluntariamente com a investigação e com o processo criminal" (BRASIL, 2013, Art. $\left.4^{\circ}\right)$.

Por conseguinte, o delator tem direitos, que estão elencados na Lei 12.850/13, e devem ser apresentados ao delator e seu defensor:

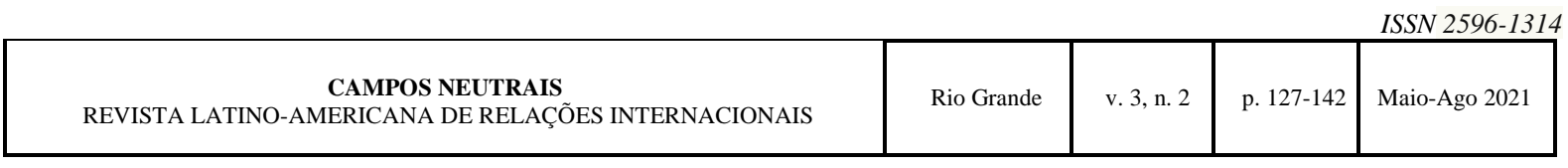


I - usufruir das medidas de proteção previstas na legislação específica;

II - ter nome, qualificação, imagem e demais informações pessoais preservados;

III - ser conduzido, em juízo, separadamente dos demais coautores e partícipes;

IV - participar das audiências sem contato visual com os outros acusados;

V - não ter sua identidade revelada pelos meios de comunicação, nem ser fotografado ou filmado, sem sua prévia autorização por escrito

VI - cumprir pena em estabelecimento penal diverso dos demais corréus ou condenados (BRASIL, 2013, Art. $5^{\circ}$ ).

Contudo, os direitos acima apresentados, podem ser, tanto no momento da assinatura do acordo como posteriormente, abdicados pelo delator. Além disso, o Ministério Público não tem obrigação de aceitar o instituto da delação premiada, avaliando qual a sua real necessidade para a identificação das provas de investigação.

Outra questão importante, refere à utilização das informações apresentadas no momento da delação. Para utilizar as informações advindas da colaboração "para sustentar um juízo condenatório, ostentando a condição de meio de prova, é possível submeter o agente colaborador ao contraditório em juízo" (ENCCLA, 2014, p. 13).

Deve ser observado, quando da utilização do instituto da delação premiada, a proporcionalidade dos benefícios concedidos com a relevância das informações apresentadas pelo colaborador.

\section{A Operação Lava Jato}

Uma das operações de investigação mais comentadas no país (se não a mais) é a Operação Lava Jato.

O processo investigativo teve início em 2009, a partir da investigação de lavagem de dinheiro relacionada ao ex-deputado federal José Janene, no Paraná, também estavam envolvidos os doleiros Alberto Youssef ${ }^{2}$ e Carlos Habib Chater (MPF, 2019).

A operação ganhou o nome de Lava Jato, em decorrência de uma das organizações criminosas $^{3}$ investigadas utilizar uma rede de postos de combustíveis e lava jato para a

\footnotetext{
2 “Personagem central do caso Lava Jato, já foi investigado, processado e preso, em 2003, em decorrência de sua atuação no mercado clandestino de dólares, após a apuração de um dos maiores esquemas criminosos que já existiu, o "Esquema CC5", também conhecido como "Caso Banestado". Youssef foi um dos maiores doleiros do Brasil, atuando no mercado atacadista, em que provia dólares para outros doleiros e alguns clientes especiais. Isso acontecia, basicamente, de três formas" (MPF, s/d).

${ }^{3}$ Organização criminosa é "a associação de 4 (quatro) ou mais pessoas estruturalmente ordenada e caracterizada pela divisão de tarefas, ainda que informalmente, com objetivo de obter, direta ou indiretamente, vantagem de qualquer natureza, mediante a prática de infrações penais cujas penas máximas sejam superiores a 4 (quatro) anos, ou que sejam de caráter transnacional” (BRASIL, 2013, Art. 1, § 19).
} 


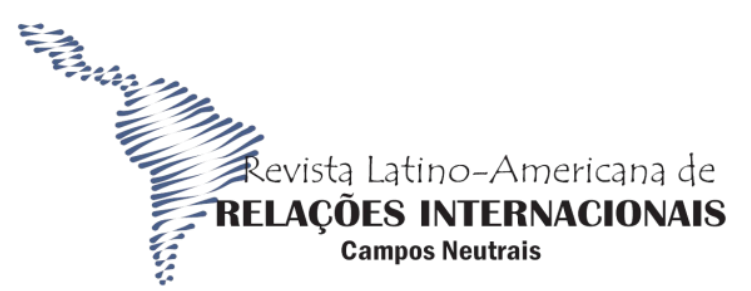

FURG

movimentação e a lavagem dos ganhos ilícitos (as investigações apontam para Chater como líder da organização). Mesmo a investigação sendo estendida, ao longo do tempo, para outras organizações criminosas, o nome se manteve (MPF, 2019).

De acordo com o MPF (2019), em meados de 2013, foi iniciado o monitoramento telefônico das conversas do doleiro Chater. A partir destas comunicações, a investigação conseguiu identificar diversas organizações criminosas comandadas por doleiros e relacionadas entre si. Através dos chamados "grampos telefônicos", também, foi revelado que "Alberto Youssef, mediante pagamentos feitos por terceiros, 'doou' um Land Rover Evoque para o ex-diretor de Abastecimento da Petrobras Paulo Roberto Costa" (MPF, 2019).

No dia 17 de março de 2014, foi deflagrada a primeira fase ostensiva da operação, objetivando a investigação do esquema de lavagem de dinheiro relacionados à Petrobras ${ }^{4}$, agentes políticos ${ }^{5}$ e grandes empreiteiras ${ }^{6}$ do país. Na ocasião:

O ex-diretor da Petrobras Paulo Roberto Costa foi preso e foram cumpridos seis mandados de busca e apreensão no Rio de Janeiro. Em seguida, os procuradores da República do caso viriam a acusar o ex-diretor e seus familiares pelo crime de obstrução à investigação de organização criminosa.

\footnotetext{
${ }^{4}$ De acordo com as investigações, "os funcionários não só se omitiam em relação ao cartel, do qual tinham conhecimento, mas o favoreciam, restringindo convidados e incluindo a ganhadora dentre as participantes, em um jogo de cartas marcadas. Segundo levantamentos da Petrobras, eram feitas negociações diretas injustificadas, celebravam-se aditivos desnecessários e com preços excessivos, aceleravam-se contratações com supressão de etapas relevantes e vazavam informações sigilosas, dentre outras irregularidades" (MPF, 2019).

${ }^{5}$ No ano de 2015, o "Procurador-Geral da República apresentou ao Supremo Tribunal Federal 28 petições para a abertura de inquéritos criminais destinados a apurar fatos atribuídos a 55 pessoas, das quais 49 são titulares de foro por prerrogativa de função ("foro privilegiado"). São pessoas que integram ou estão relacionadas a partidos políticos responsáveis por indicar e manter os diretores da Petrobras. Elas foram citadas em colaborações premiadas feitas na 1 a instância mediante delegação do Procurador-Geral. A primeira instância investigará os agentes políticos por improbidade, na área cível, e na área criminal aqueles sem prerrogativa de foro" (MPF, 2019).

${ }^{6}$ Segundo as investigações, "as empreiteiras se cartelizaram em um "clube" para substituir uma concorrência real por uma concorrência aparente. Os preços oferecidos à Petrobras eram calculados e ajustados em reuniões secretas nas quais se definia quem ganharia o contrato e qual seria o preço, inflado em benefício privado e em prejuízo dos cofres da estatal" (MPF, 2019).
}

\begin{tabular}{|c|c|c|c|c|}
\hline $\begin{array}{l}\text { CAMPOS NEUTRAIS } \\
\text { REVISTA LATINO-AMERICANA DE RELAÇÕES INTERNACIONAIS }\end{array}$ & Rio Grande & v. 3, n. 2 & p. $127-142$ & Maio-Ago 2021 \\
\hline
\end{tabular}




\begin{abstract}
Nessas medidas iniciais, mais de 80 mil documentos foram apreendidos pela Polícia Federal, além de diversos equipamentos de informática e celulares. A análise desse material somou-se aos monitoramentos de conversas e aos dados bancários dos investigados que foram coletados e analisados eletronicamente no sistema Simba (Sistema de Investigação de Movimentações Bancárias), do Ministério Público Federal. [...]

Para analisar todo o material apreendido nas primeiras etapas da investigação e propor acusações, o procurador-geral da República, Rodrigo Janot, designou, em abril, um grupo de procuradores da República. No mês que se seguiu, os integrantes dessa força-tarefa_chegaram às conclusões que culminaram no oferecimento das primeiras denúncias (MPF, 2019).
\end{abstract}

Neste esquema de corrupção, que, segundo o MPF (2019), ocorre a pelo menos dez anos:

[...] grandes empreiteiras organizadas em cartel pagavam propina para altos executivos da estatal e outros agentes públicos. O valor da propina variava de $1 \%$ a $5 \%$ do montante total de contratos bilionários superfaturados. Esse suborno era distribuído por meio de operadores financeiros do esquema, incluindo doleiros investigados na primeira etapa (MPF, 2019).

Ainda, em 2014, foi assinado o primeiro acordo de delação premiada com o Ministério Público, relacionado à Lava Jato. O delator foi Paulo Roberto Costa, que “entregou 'algumas dezenas' de políticos em depoimentos sigilosos à Justiça” (CIOCCARI, 2015, p. 74). Na sequência, Alberto Youssef também assinou o acordo de delação premiada em troca de benefícios.

No mês de novembro, do mesmo ano, foi deflagrada uma nova fase da Lava Jato, realizando buscas em diversas companhias, entre elas as empreiteiras Odebrecht, Camargo Corrêa e OAS. Esta fase culminou com as denúncias do Ministério público sendo acatadas, e 39 pessoas se tornaram rés (CIOCCARI, 2015).

Conforme demonstra o MPF (2019), as investigações continuam e se encontram em sua $60^{\mathrm{a}}$ fase. Até o momento, a operação instaurou 2.476 procedimentos: 1.237 mandados de buscas e apreensões, 227 mandados de condução coerciva, 161 mandados de prisões preventivas, 155 mandados de prisões temporárias e 6 prisões em flagrante. Ainda, segundo este órgão, foram realizas 99 acusações criminais contra 438 pessoas, com atualmente, 50 sentenças por diversos crimes, entre eles crimes de corrupção, crimes contra o sistema financeiro internacional, tráfico transnacional de drogas, formação de organização criminosa e lavagem de dinheiro.

Além disso, até o momento, já foram firmados 184 acordos de delação premiada e aproximadamente R $\$ 13$ bilhões são alvo de recuperação através destes acordos (MPF, 2019). 


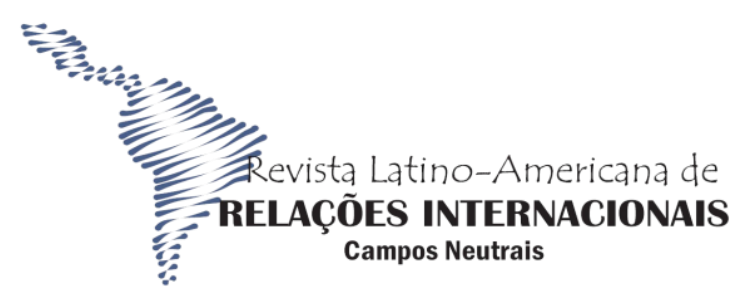

\section{A delação premiada e a Operação Lava Jato}

Os crimes relacionados à corrupção e à lavagem de dinheiro não são fáceis de desvendar. Essa dificuldade pode ser ampliada quando os investigados são os agentes públicos de alto escalão:

[...] ações contra o patrimônio público costumam ser bem distintas daquelas, mais visíveis, de banditismo comum. Exigem alto grau de complexidade, com o emprego de mecanismos que procuram dar às transações a aparência de legalidade, blindando arranjos cuja descoberta, quase sempre, depende da colaboração dos próprios envolvidos (SENADO FEDERAL, 2019).

A delação premiada emerge como um instrumento valioso de obtenção de provas e de colaboração, tendo em conta, a possibilidade de o delator receber benefícios como a redução de pena.

Conforme apresentado no tópico 2.3, a Lava Jato já soma 184 delações premiadas (MPF, 2019) e de acordo com Passarelli (2016):

[...] o acordo tem sido o principal meio empregado pela força-tarefa da Operação [...], liderada pela Polícia Federal, que foi iniciada investigando apenas alguns doleiros envolvidos em desvios de dinheiros da Petrobras, e atualmente é considerada uma das maiores operações contra a corrupção no país (PASSARELLI, 2016).

Porém, as opiniões, quanto à efetividade da delação premiada, são divididas. Nucci (2008), realiza um trabalho apresentando as vantagens e desvantagens deste instituto. Além do referido autor, diversos juristas apresentam seus prós e os seus contras.

Pensando inicialmente na questão moral e ética, no acordo de delação premiada:

[...] oficializa-se, por lei, a traição, forma antiética de comportamento social; [...] [contudo] no universo criminoso, não se pode falar em ética ou valores moralmente elevados, dada a própria natureza da prática de condutas que rompem com as normas vigentes, ferindo bens jurídicos protegidos pelo Estado (NUCCI, 2008, p, 1024-1025).

Para Lerovin (2018):

[...] a delação premiada flexibiliza as garantias penais e processuais, através da instrumentalização midiática, para otimizar a suposta efetividade, deixando de observar os valores e limites instituídos no padrão de constitucionalidade e convencionalidade. A política criminal, por decorrência, passa a sofrer significativa influência da pressão social (LEROVIN, 2018, p. 14).

\begin{tabular}{|c|c|c|c|c|}
\hline $\begin{array}{l}\text { CAMPOS NEUTRAIS } \\
\text { REVISTA LATINO-AMERICANA DE RELAÇÕES INTERNACIONAIS }\end{array}$ & Rio Grande & v. 3, n. 2 & p. $127-142$ & Maio-Ago 2021 \\
\hline
\end{tabular}


No mesmo sentido, Lopes Jr. (2016) discorre sobre as declarações apresentadas pelo delator e seus impactos, contraproducentes, na investigação e no processo penal:

[...] o pacto no processo penal é um perverso intercâmbio, que transforma a acusação em um instrumento de pressão, capaz de gerar autoacusações falsas, testemunhos caluniosos por conveniência, obstrucionismo ou prevaricações sobre a defesa, desigualdade de tratamento e insegurança (LOPES JR., 2016, p. 796).

Replicando o argumento de Lopes Jr. (2016), “a falsa delação, embora possa existir, deve ser severamente punida" (NUCCI, 2008, p. 1025).

Não menos importante, é tratar da possibilidade da credibilidade nas instituições da justiça criminal no Brasil ser abalada, pois os benefícios do referido instituto podem ser identificados como "inadequada atenuação ao princípio da obrigatoriedade da ação penal" (LEVORIN, 2018, p. 115),

O princípio da obrigatoriedade da ação penal:

[...] (também conhecido como princípio da legalidade, da oficialidade, da necessidade ou indisponibilidade), o Parquet vê-se obrigado a oferecer a denúncia, iniciando o processo penal, assim que tomar conhecimento de uma conduta típica, antijurídica e agente culpável, havendo indícios suficientes de autoria e materialidade (OLIVEIRA, 2017, p. 239).

A atenuação deste princípio se materializaria quando da possibilidade do perdão judicial ao infrator que assinar o acordo de delação premiada. Um destes exemplos foi o “acordo de delação premiada dos irmãos Joesley e Wesley Batista que descrevem 240 condutas criminosas, que poderiam redundar de 400 até 2000 anos de pena privativa de liberdade, mas que receberam o perdão judicial” (LEVORIN, 2018, p. 114-115).

Além disso, pode-se entender que o princípio da proporcionalidade da pena também esteja sendo ferido. Contudo, Nucci (2008, p. 1025) rebate esta crítica, afirmando que "não há lesão à proporcionalidade na aplicação da pena, pois esta é regida, basicamente, pela culpabilidade (juízo de reprovação social), que é flexível”. Nucci (2008, p. 1024) se utiliza da argumentação de que "o Estado não pode aquiescer em barganhar com a criminalidade. Além disso:

No Direito Penal Brasileiro, a prova mais relevante é a pericial, técnica, científica. Assim, a delação - prova testemunhal - possui menor valor, ainda mais em se tratando de um testemunho de um criminoso sem qualquer interesse primário em colaborar com a Justiça, e sim apenas em obter para si um proveito próprio (BRILHANTE, 2016).

A reflexão de Nucci (2008) sobre a matéria, parece conseguir descrever a percepção do instituto da delação premiada, no geral:

[...] parece-nos que a delação premiada é um mal necessário, pois o bem maior a ser tutelado é o Estado Democrático de Direito. Não é preciso ressaltar que o crime organizado tem ampla penetração nas entranhas estatais e possui condições de 


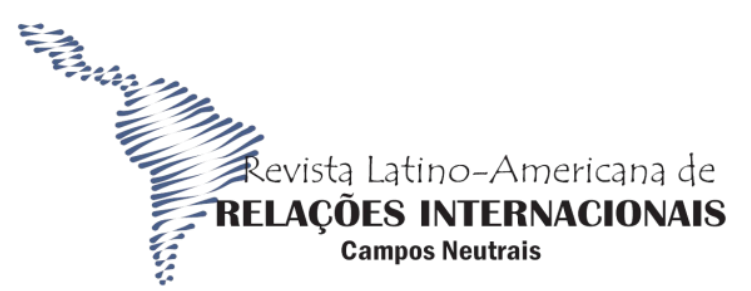

FURG

\begin{abstract}
desestabilizar qualquer democracia, sem que se possa combatê-lo, com eficiência, desprezando-se a colaboração daqueles que conhecem o esquema e dispõem-se a denunciar coautores e partícipes. No universo de seres humanos de bem, sem dúvida, a traição é desventurada, mas não cremos que se possa dizer o mesmo ao transferirmos nossa análise para o âmbito do crime, por si só, desregrado, avesso à legalidade, contrário ao monopólio estatal de resolução de conflitos, regido por leis esdrúxulas e extremamente severas, totalmente distante dos valores regentes dos direitos humanos fundamentais. (Nucci, 2008, p. 418).
\end{abstract}

Através deste artifício, pode-se identificar os envolvidos nos crimes de corrupção e lavagem de dinheiro, além de facilitar exposição da estrutura hierárquica da organização criminosa investigada, com a possibilidade de recuperação dos prejuízos financeiros causados ao erário público. Isto é, a facilitação da junção de provas que seriam de difícil acesso caso o delator se mantivesse em silêncio.

\title{
Considerações Finais
}

Neste trabalho foi abordado o assunto do instituto da delação premiada nas investigações da Operação Lava Jato sobre o esquema de corrupção e lavagem de dinheiro envolvendo os dirigentes da Petrobras, agentes políticos e grandes empreiteiras do país. Esse instituto é um benefício ao réu que, de forma voluntária, colabore com as investigações e cujas informações apresentadas auxiliem, efetivamente, na identificação dos líderes e no desmantelamento de organização criminosa, além de proporcionar a recuperação do produto do crime.

Como pôde ser identificado ao longo do trabalho, existem muitos argumentos doutrinários criticando os acordos de delação premiada, porque este possibilitaria ao delator diversos benefícios, tais como redução e até mesmo extinção da pena, o que poderia abalar a credibilidade nas instituições da justiça criminal brasileira. Todavia, foi possível concluir, através dos dados apresentados durante o trabalho, que na Operação Lava Jato o instituto da delação premiada se tornou o principal instrumento de obtenção de provas nas investigações para o desmantelamento do esquema de corrupção envolvendo o setor público e o setor privado e com isso, identificou centenas de políticos e grandes empresários envolvidos com nos crimes contra os cofres públicos.

\begin{tabular}{|c|c|c|c|c|}
\hline \multicolumn{1}{|c|}{ ISSN 2596-1314 } \\
\begin{tabular}{|l|l|l} 
CAMPOS NEUTRAIS \\
REVISTA LATINO-AMERICANA DE RELAÇÕES INTERNACIONAIS
\end{tabular} & Rio Grande & v. 3, n. 2 & p. 127-142 & Maio-Ago 2021 \\
\hline
\end{tabular}


Tratar sobre este tema é muito importante, pois clarifica a importância e as contribuições da delação premiada para a justiça penal brasileira, na medida que reprime a corrupção, a lavagem de dinheiro e possibilita a obtenção de provas que seriam de difícil acesso, tendo em conta que a elaboração e minúcias dos crimes envolvem criminosos com o poder político e econômico.

\section{Referências Bibliográficas}

ARAS, V. A técnica de colaboração premiada. 2015. Disponível em: <https://vladimiraras.blog/2015/01/07/a-tecnica-de-colaboracao-premiada/>. Acessado em: 10/09/2019.

ARAÚJO, M.; SANCHEZ, O. A corrupção e os controles internos do Estado. Lua Nova, vol. 65 , p. 137-173, 1996.

BORGES, D.J.L. Colaboração Premiada: Evolução normativa e questões jurídicas relevantes. CONAMP: Associação Nacional dos Membros do Ministério público, 2016. Disponível em: <https://www.conamp.org.br/pt/biblioteca/artigos/item/1097-colaboracaopremiada-evolucao-normativa-e-questoes-juridicas-relevantes.html>. Acessado em: $11 / 09 / 2019$.

BRASIL. Decreto no 154 de 26 de junho de 1991. Promulga a Convenção Contra o Tráfico Ilícito de Entorpecentes e Substâncias Psicotrópicas, 1991. Disponível em: <http://www.planalto.gov.br/ccivil_03/decreto/1990-1994/d0154.htm>. Acessado em: 12/09/2019.

BRASIL. Lei $\mathbf{n}^{\circ} \mathbf{1 2 . 6 8 3}$, de 9 de julho de 2012. Altera a Lei $n^{\circ} 9.613$, de 3 de março de 1998, para tornar mais eficiente a persecução penal dos crimes de lavagem de dinheiro, 2012. Disponível em: <http://www.planalto.gov.br/ccivil_03/_ato20112014/2012/lei/112683.htm>. Acessado em: 12/09/2019.

BRASIL. Lei $\mathbf{n}^{\circ} \mathbf{1 2 . 8 5 0}$, de 2 de agosto de 2013. Define organização criminosa e dispõe sobre a investigação criminal, os meios de obtenção da prova, infrações penais correlatas e o procedimento criminal; altera o Decreto-Lei n ${ }^{\circ} 2.848$, de 7 de dezembro de 1940 (Código Penal); revoga a Lei $n^{\circ}$ 9.034, de 3 de maio de 1995; e dá outras providências, 2013. Disponível em: <http://www.planalto.gov.br/ccivil_03/_Ato20112014/2013/Lei/L12850.htm>. Acessado em: 12/09/2019.

BRASIL. Lei n⿳ 9.613, de 3 de março de 1998. Dispõe sobre os crimes de "lavagem" ou ocultação de bens, direitos e valores; a prevenção da utilização do sistema financeiro para os ilícitos previstos nesta Lei; cria o Conselho de Controle de Atividades Financeiras COAF, e dá outras providências, 1998. Disponível: <http://www.planalto.gov.br/ccivil_03/LEIS/L9613.htm>. Acessado em: 11/09/2019.

BRILHANTE, R. 2016. Delação premiada. Disponível em: <https://jus.com.br/artigos/46491/delacao-premiada>. Acessado em: 14/09/2019. 


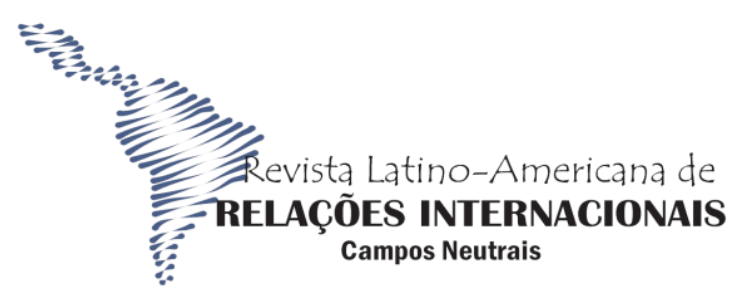

FURG

CIOCCARI, D. Operação Lava Jato: escândalo, agendamento e enquadramento. Revista Alterjor: ECA-USP, Ano 6, Vol. 02, ed. 12, jul-dez, 2015. Disponível em: $<$ https://www.revistas.usp.br/alterjor/article/view/aj12-a04/aj12-a4>. Acessado em: 13/09/2019.

\section{ENCCLD - Estratégia Nacional de Combate à Corrupção e à Lavagem de Dinheiro.}

Manual de Colaboração Premiada. Brasília, 2014. Disponível em: <http://www.mpf.mp.br/atuacao-tematica/sci/dados-da-atuacao/eventos-2/eventosinternacionais/conteudo-banners-1/enccla/restrito/manual-colaboracao-premiadajan14.pdf/view>. Acessado em: 13/09/2019.

HODESS, R., Introduction. In: HODESS, R.; INOWLOCKI, T.; RODRIGUEZ D. \& WOLFE, T. (orgs.), Global Corruption Report 2004. Londres, PlutoPress, 2004.

LEVORIN, M.P. Delação premiada: uma abordagem a partir das políticas criminais garantista e antigarantista e da Constituição Federal - 1. ed. - Jundiaí [SP]: Paco, 2018.

LOPES JR. A. Direito processual penal. 13. ed. São Paulo: Saraiva, 2016.

MINISTÉRIO DA ECONOMIA. Cartilha - Lavagem de dinheiro: um problema mundial. Conselho de Controle de Atividades Financeiras (COAF), 2015. Disponível em: $<$ http://webcache.googleusercontent.com/search?q=cache:DsV5ucTSUbwJ:www.fazenda. gov.br/centrais-de-conteudos/publicacoes/cartilhas/arquivos/cartilha-lavagem-de-dinheiroum-problema-mundial.pdf/view $+\& \mathrm{~cd}=1 \& \mathrm{hl}=\mathrm{pt}-$

BR\&ct=clnk\&gl=br\&lr=lang_es\%7Clang_pt $>$. Acessado em: 11/09/2019.

MIRANDA, L.F. Unificando os conceitos de corrupção: uma abordagem através da nova metodologia dos conceitos. Revista Brasileira de Ciência Política, nº 25. Brasília, janeiro abril, p. 237-272, 2018.

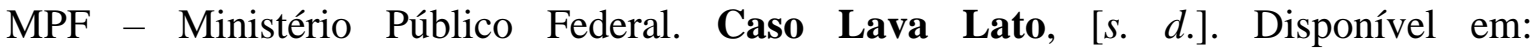
<http://www.mpf.mp.br/grandes-casos/caso-lava-jato/atuacao-na-1a-instancia/parana/ resultado>. Acessado em: 12/09/2019.

MPF - Ministério Público Federal. O Caso Banestado. [s. d.(b)]. Disponível em: $<$ http://www.mpf.mp.br/grandes-casos/caso-lava-jato/atuacao-na-1a-instancia/investigacao /relacao-com-o-caso-banestado>. Acessado em: 12/09/2019.

NUCCI, G.S. Código de Processo Penal Comentado. 8 ed. São Paulo: Revista dos Tribunais, 2008a.

NUCCI, G.S. Manuel de Processo Penal e Execução penal. São Paulo: RT, 2008

OLIVEIRA, T.L.M. O mito da obrigatoriedade da ação penal no ordenamento jurídico brasileiro. Boletim Científico ESMPU, Brasília, ano 16 - n. 49, p. 237-262 - jan./jun., 2017.

SENADO FEDERAL. Coação e afronta, 2019. Disponível em: <https://www2.senado.leg.br/bdsf/bitstream/handle/id/509020/noticia.html?sequence=1>. Acessado em: 13/09/2019. 
Marcia Leite Borges; Luciano Duarte da Silva

TI - Transparência Internacional. Quem somos, 2019. Disponível em: <https://transparenciainternacional.org.br/quem-somos/sobre-a-ti/>. Acessado em: $17 / 09 / 2019$. 